\title{
A Novel UWB Monopole Antenna with Defected Ground Structure
}

\author{
V. N. Koteswara Rao. Devana \\ Assistant Professor, SACET, Chirala, AP, India . \\ dvnkrao@gmail.com
}

\begin{abstract}
A novel modified Ultra Wideband (UWB) compact planar monopole antenna fed by a 50- $\Omega$ micro stripline suitable for ultra wideband applications is presented. This microstrip-fed antenna, consisting of two L-shaped slots on the radiating patch and consisting of two rectangular slots and a square slot on the ground plane. The designed antenna has a small size of $11 \times 16 \times 1.6 \mathrm{~mm}^{3}$ and operates over the frequency band between 4.1 and $12 \mathrm{GHz}$ for VSWR $<2$, with an impedance bandwidth of $97.23 \%$, and is suitable for applications of wireless communications and high resolution microwave imaging systems. The proposed UWB antenna is simulated by using the CST Microwave studio. Details of the proposed antenna design and the simulated results are presented.
\end{abstract}

Keywords: Ultra Wideband (UWB) antenna, monopole antenna, Microstrip-feed

\section{Introduction}

Nowadays, the antennas with wideband characteristics are in high demand to meet the requirements of current high data rate wireless communication systems. To achieve this wide band width requirement Microstrip Antennas are used. The Microstrip antennas are the most preferred one for small handheld devices and WLAN cards due to their number of inherent advantages. A microstrip antenna basically consists of a radiating patch placed on a dielectric substrate attached to a ground plane. The conducting patch is usually made with copper or gold and it can be designed in variety of shapes. The conducting patch and the feed lines are connected to the dielectric using photo etching method.

These antennas radiate primarily because of the fringing fields developed between the radiating patch and the ground plane. For achieving larger bandwidth and good radiation efficiency, usually the antennas with high dielectric constant and low permittivity value are desired. However, it increases the antenna size. Hence, a compromise is to be reached between antenna performance and antenna size. These antennas are fed with different feeding mechanism like microstrip feed, coaxial feed, aperture coupled feed and proximity coupled feed. In the first two methods, the RF power is fed directly to the radiating patch and these are known as contacting schemes. In the later two methods, the electromagnetic coupling is used to transfer the power from microstrip line to the radiating patch and these are known as non contacting schemes. The microstrip antennas are available in different shapes like square, rectangular, circular, elliptical, triangular, etc.

Since, the Federal Communication Commission (FCC) introduced the unlicensed ultrawideband (UWB) frequency band from 3.1 to $10.6 \mathrm{GHz}$ (i.e., a $109.5 \%$ fractional bandwidth) for commercial communication application, many types of UWB antennas have been developed. Ultra Wide Band (UWB), a radio transmission technology which occupies an extremely wide bandwidth exceeding the minimum of $500 \mathrm{MHz}$ or atleast $20 \%$ of the centre frequency, is a revolutionary approach for short-range high bandwidth wireless communication. Differing from traditional narrow band radio systems(with a bandwidth usually less than $10 \%$ of the centre frequency) transmitting signals by modulating the amplitude, frequency or phase of the sinusoidal waveforms, UWB systems 
transmit information by generating radio energy at specific time instants in the form of very short pulses thus occupying very large bandwidth and enabling time modulation.

Due to transmission of non-successive and very short pulses, UWB radio propagation will provide very high data rates which may be up to several hundred Megabytes per second, and it is difficult to track the transmitting data, which highly ensures the data security. For the same reason, the transmitting consumption of UWB systems is extremely low in comparison with that of traditional narrow band radio systems. Moreover, the short pulses give rise to avoidance of multipath fading since the reflected signals do not overlap the original ones. Because of these alluring properties, UWB technology is employed in many applications such as indoor positioning, radar/medical imaging and target sensor data collection. One of the challenges for the implementation of UWB systems is the development of a suitable or optimal antenna. The first important requirement for the designing an UWB antenna is the extremely wide bandwidth.

Recently, Ultra wideband (UWB) technology has been widely used in various communication systems and wireless applications, for enabling high data rates, increased communication security, low power consumption and simple hardware configuration in practical applications. The United States, Federal Communication Commission (FCC) define frequency band from 3.1 to $10.6 \mathrm{GHz}$ for unlicensed wireless communication including VSWR less than 2.0, omnidirectional radiation patterns, minimum distortions in the received waveforms, etc., [1]. Among the various UWB antennas, the planar configuration has been of particular interest because of its superior performance characteristics. Those include compact size, lower profile, and simpler structure, which lead to lower costs, easy fabrication, and convenient integration with monolithic RF circuits. The performance of the UWB antennas in both time and frequency domain are of equally importance which makes the UWB antenna design a challenging and interesting field of research [2-5]. As the key component of the UWB wireless communication system, the UWB antenna has drawn increasing attention [6].

Monopole antennas with microstrip feed line are widely used in designing UWB antenna because of low profile, low cost, light weight, easy fabrication, designing in desirable shape and integration with printed circuit boards. They also have UWB impedance matching (more than 100\%). The printed monopole antenna showed advantages due to its compact size, simple structure, wideband realizable characteristic, omnidirectional radiation patterns, high radiation efficiency and low cost. The patch of this type of reported antennas has different shapes such as rectangular, disc, triangle and elliptical forms [7-9]. There are many techniques that consist of changes on patch, feed line, and ground structure which is introduced as the most important of all to enhance the bandwidth and access to UWB bandwidth. Nowadays slot antennas are a typical kind of UWB antenna [10-25].

The proposed work, UWB monopole antenna is designed to operate in the UWB frequency range from 4.1 to $12 \mathrm{GHZ}$.

\section{Antenna Design}

The geometry and configuration of the final optimized UWB monopole antenna with microstrip line feeding is shown in the Figure 1. The designed antenna features a compact size of $11 \times 16 \mathrm{~mm}^{2}$ and it is printed on conventional FR4 substrate with thickness of 1.6 $\mathrm{mm}$ and relative permittivity $\left(\varepsilon_{r}\right)$ of 4.3 . The basic structure of the proposed UWB antenna consists of a rectangular radiating patch, a feed-line, two rectangular slots and a square slot on ground plane. The dimensions of the proposed UWB antenna are as shown in the Table 1. 
Table 1. Dimensions of the Proposed UWB Antenna

\begin{tabular}{|c|c|c|c|c|c|c|c|c|c|c|c|}
\hline Parameter & $\mathrm{mm}$ & Parameter & $\mathrm{mm}$ & Parameter & $\mathrm{mm}$ & Parameter & $\mathrm{mm}$ & Parameter & $\mathrm{mm}$ & Parameter & $\mathrm{mm}$ \\
\hline $\mathrm{W}_{\text {sub }}$ & 11 & $\mathrm{~L}_{\text {sub }}$ & 16 & $\mathrm{~h}_{\text {sub }}$ & 1.6 & $\mathrm{~W}_{\mathrm{f}}$ & 2 & $\mathrm{~L}_{\mathrm{f}}$ & 5.5 & $\mathrm{~W}$ & 9 \\
\hline $\mathrm{L}$ & 8.5 & $\mathrm{~W}_{1}$ & .1 & $\mathrm{~L}_{1}$ & 2 & $\mathrm{~W}_{2}$ & 1.8 & $\mathrm{~L}_{2}$ & .1 & $\mathrm{~W}_{\mathrm{g}}$ & 11 \\
\hline $\mathrm{L}_{\mathrm{g}}$ & 2.5 & $\mathrm{~W}_{\mathrm{r}}$ & 4 & $\mathrm{~L}_{\mathrm{r}}$ & 1 & $\mathrm{~W}_{\mathrm{s}}$ & 1 & $\mathrm{~L}_{\mathrm{s}}$ & 1 & $\ldots$ & $\ldots$ \\
\hline
\end{tabular}

The front view of the prosposed antenna is shown in Figure 1(a). The radiating patch is printed on the surface of the substrate with the dimension of $11 \times 16 \mathrm{~mm}^{2}$. There are two L shaped slots are etched on the radiating patch and the ground plane is etched along with the slots as shown in Figure 1(b), to achieve the ultrawideband bandwidth ranging from 4.1 and $12 \mathrm{GHz}$ for VSWR $<2$.

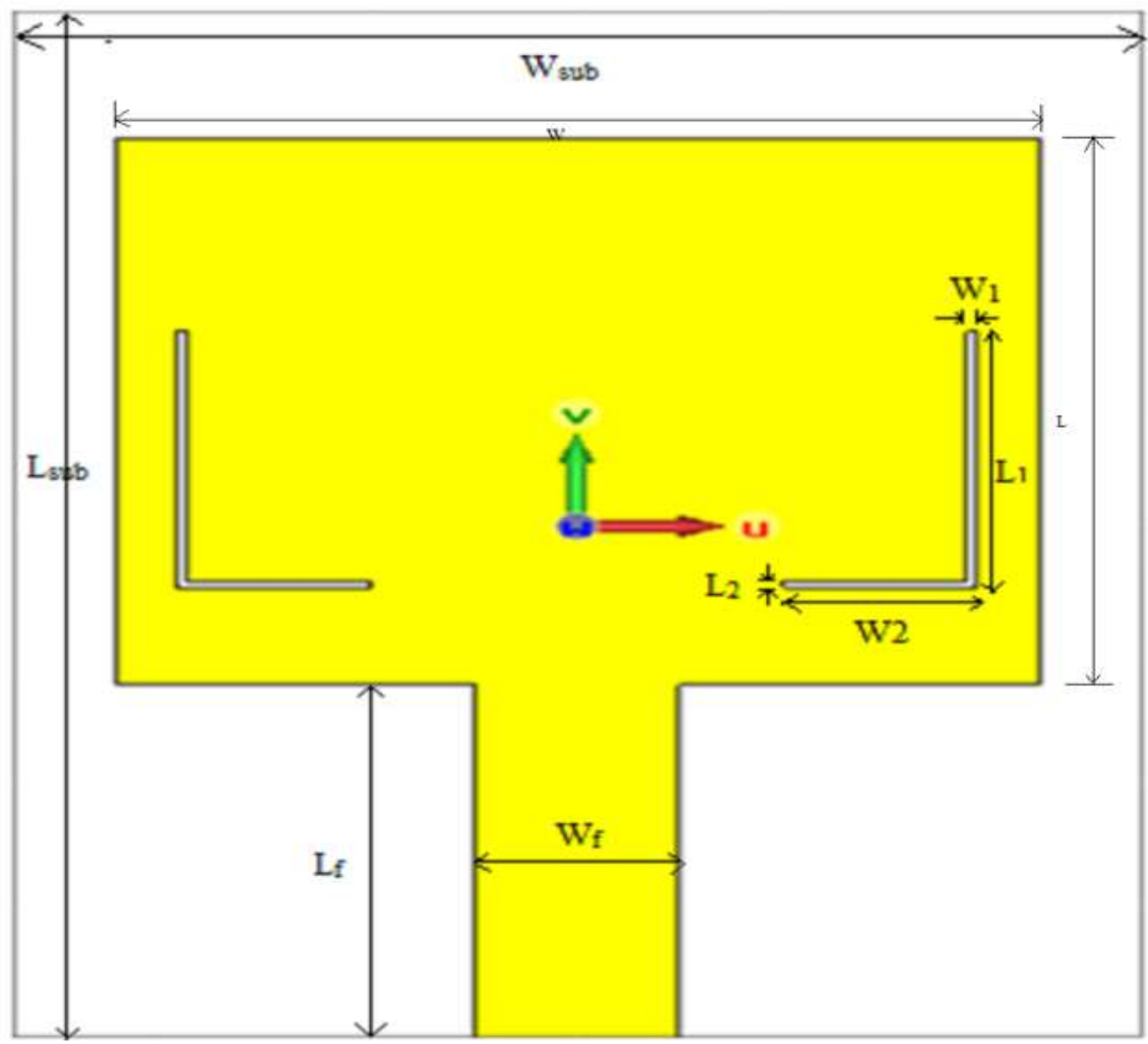

(a) Front view 


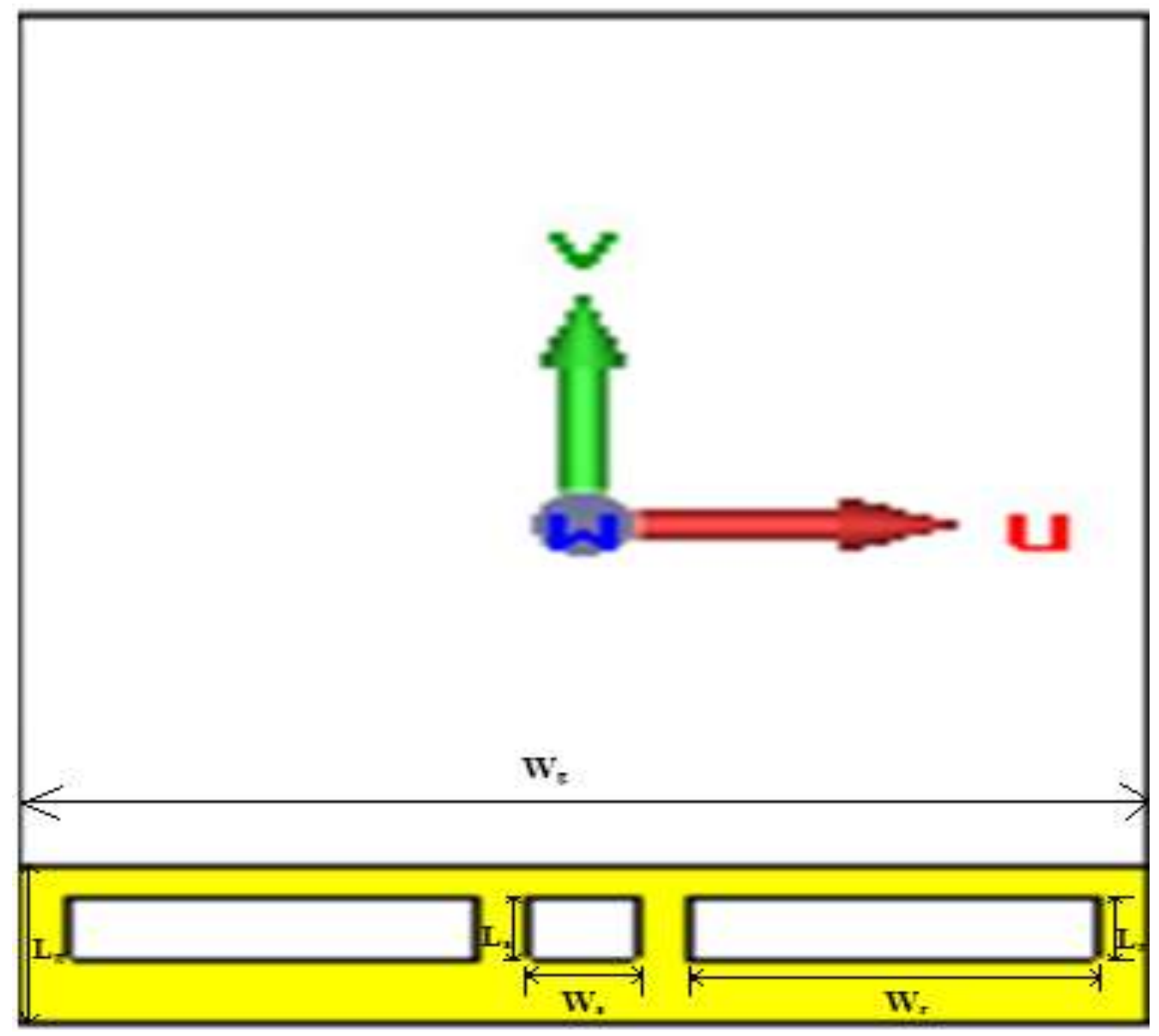

(b) Back view

Figure 1. Geometry of the Proposed UWB Antenna

There is a lot of flexibility in choosing the width of the radiating patch. This parameter mostly affects the antenna bandwidth. As width decreases, so does the antenna bandwidth, and vice versa. The length of the radiating patch depends on a number of parameters such as the radiating patch width, thickness and dielectric constant of the substrate on which the antenna is fabricated. The above proposed antenna is fed by a microstrip feed line. The optimized dimensions for the proposed antenna are shown in Table 1.

\section{Simulation Results}

The proposed UWB antenna structure is simulated with CST Microwave studio that is based on Finite Integration Technique (FIT) in the time domain []. The simulated return loss of the UWB antenna Figure 2. From Figure 2, the simulation results of the proposed UWB antenna have a wide bandwidth ranging from $4.1 \mathrm{GHz}$ to $12 \mathrm{GHz}$. The VSWR plot is shown in Figure 3. The designed antenna shows good characteristics for UWB, satisfying good VSWR less than 2 in the frequency band 4.1 to 12 GHZ. 


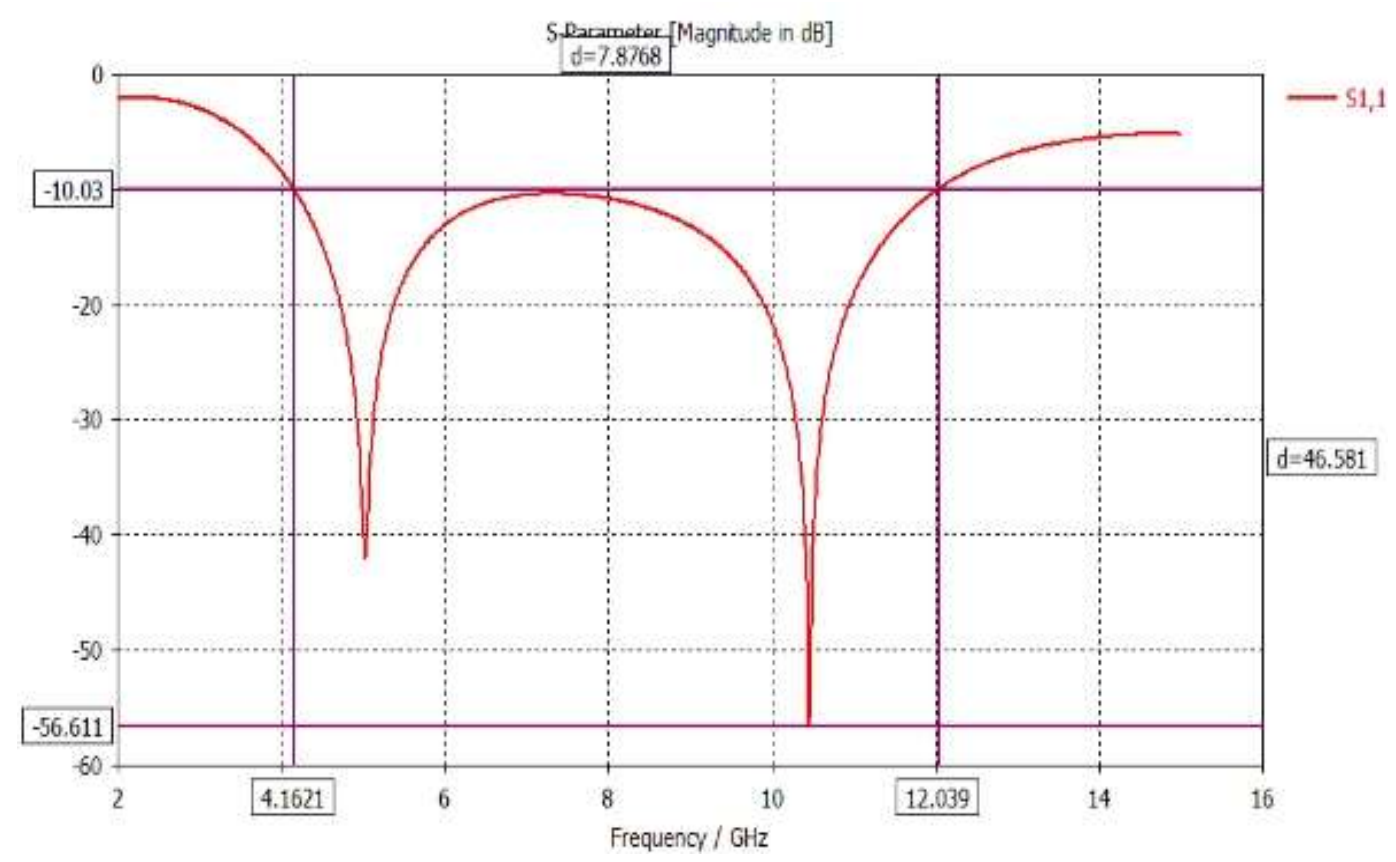

2. Return Loss of the Proposed UWB Antenna

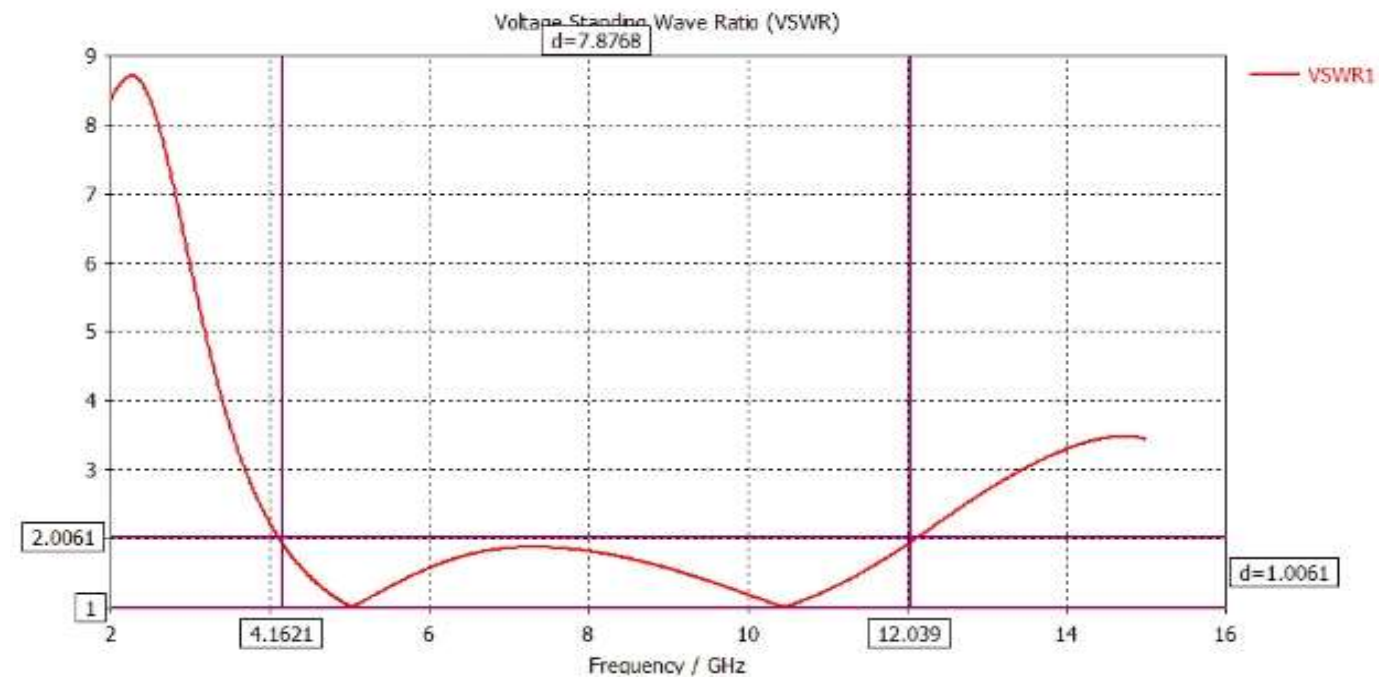

Figure 3. VSWR Plot of the Proposed UWB Antenna

The radiation patterns of the proposed antenna at $4.99 \mathrm{GHz}, 7 \mathrm{GHz}, 9 \mathrm{GHz}$ and 10.45 $\mathrm{GHz}$ are shown in the Figure 4. The 3- Dimensional Farfield radiation pattern of the proposed antenna for the above frequencies are also simulated and shown in Figure 5. 


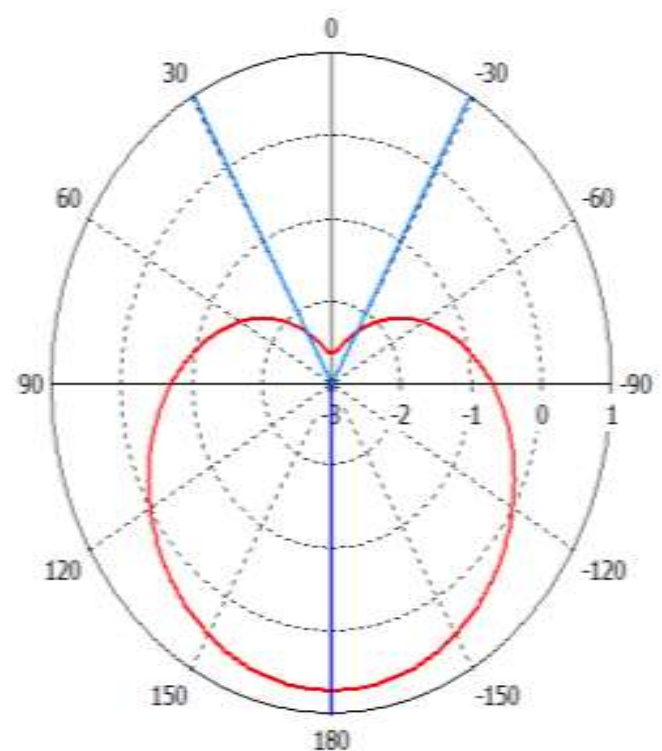

E-Plane at $4.99 \mathrm{GHz}$

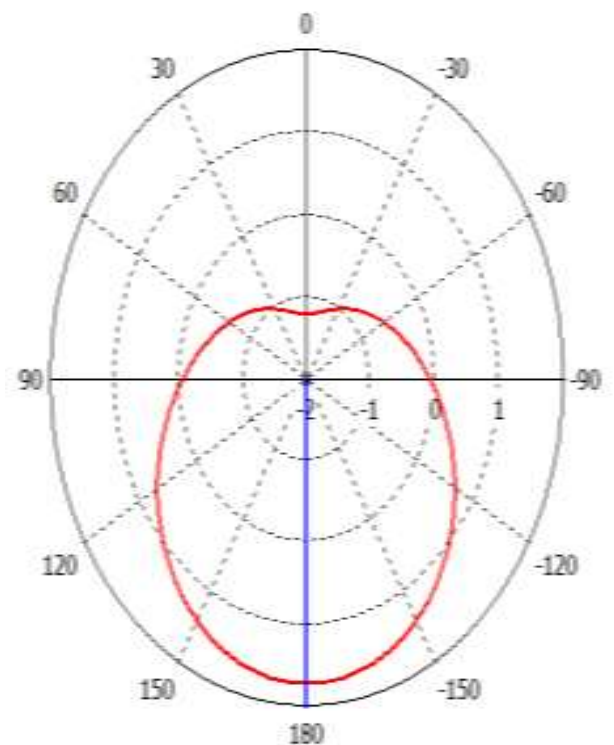

Theta / Degree vs. dB

E-Plane at $7 \mathrm{GHz}$

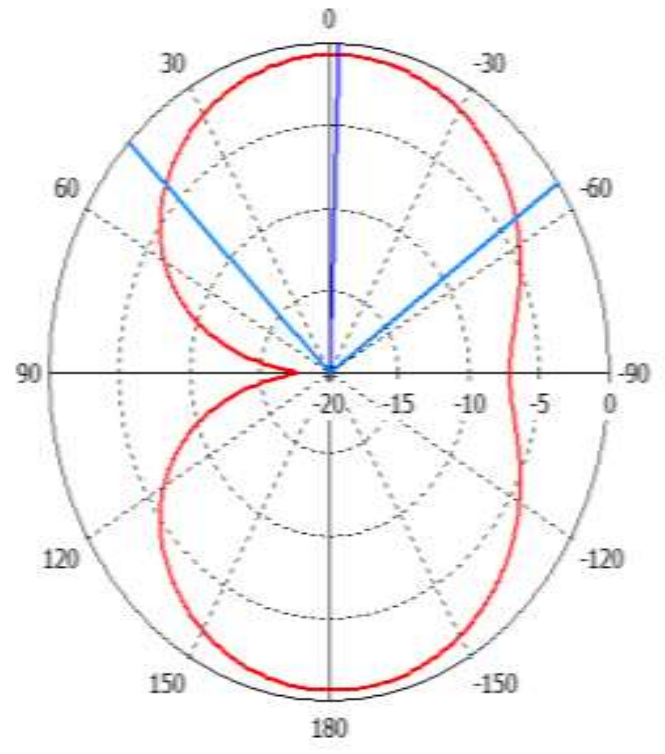

$\mathrm{H}$-Plane at $4.99 \mathrm{GHz}$

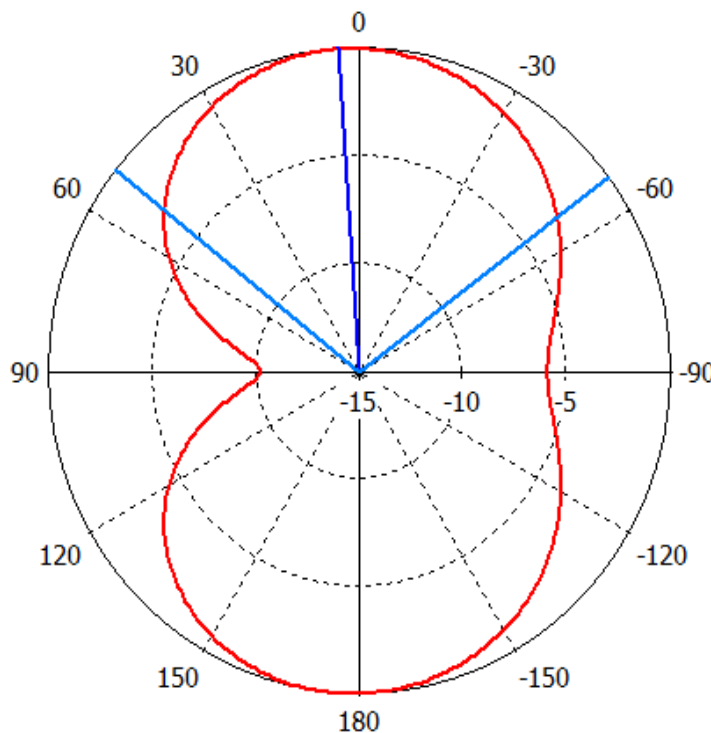

Phi / Degree vs. dB

H-Plane at $7 \mathrm{GHz}$ 


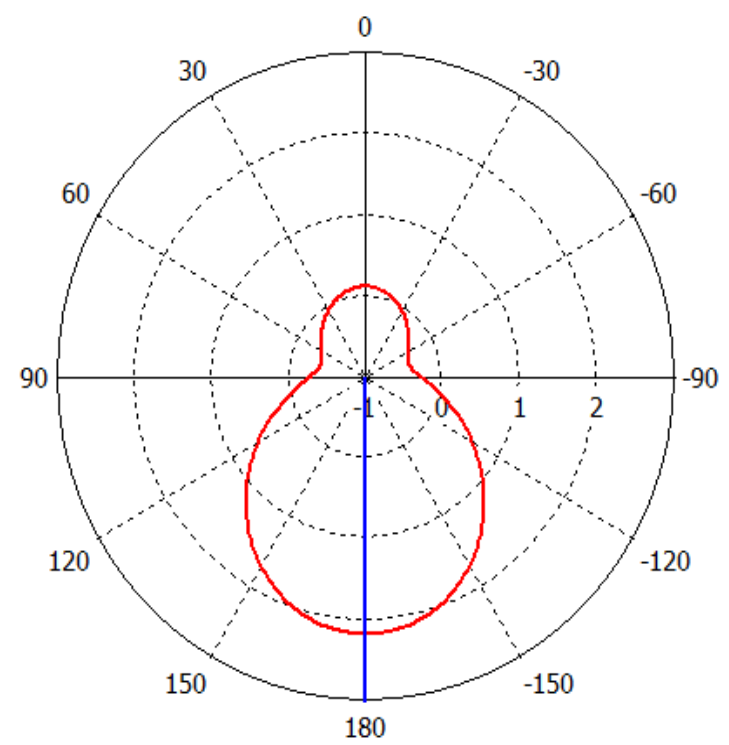

Theta / Degree vs. dB

E-Plane at $9 \mathrm{GHz}$

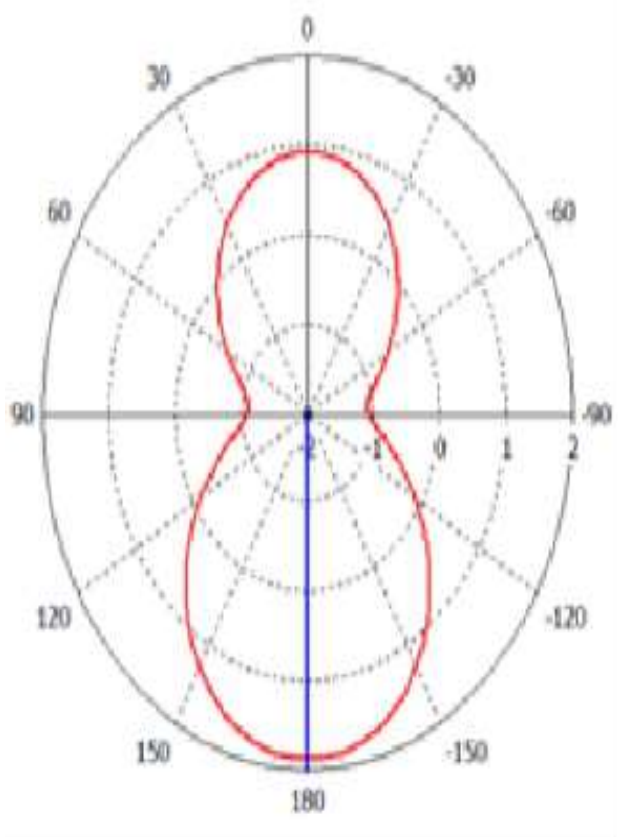

E-Plane at $10.45 \mathrm{GHz}$

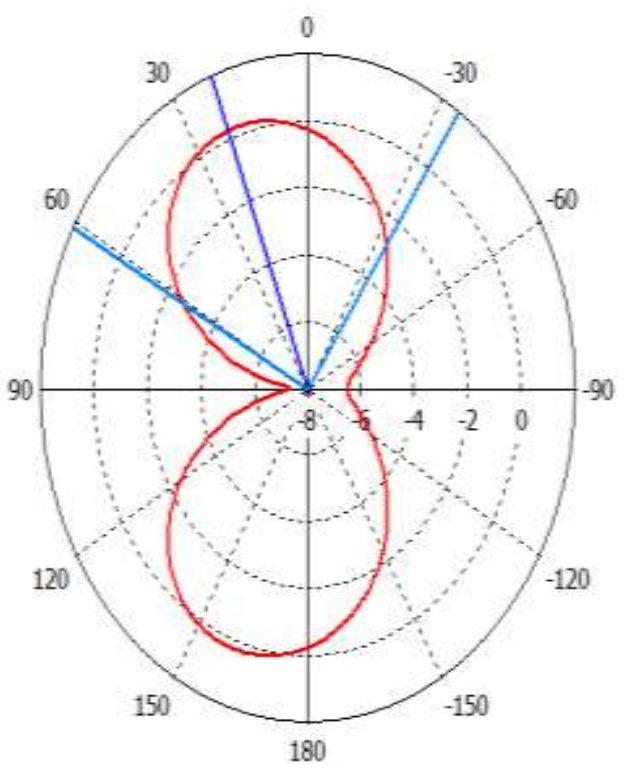

Phi/ Degree vs. dB

$\mathrm{H}$-Plane at $9 \mathrm{GHz}$

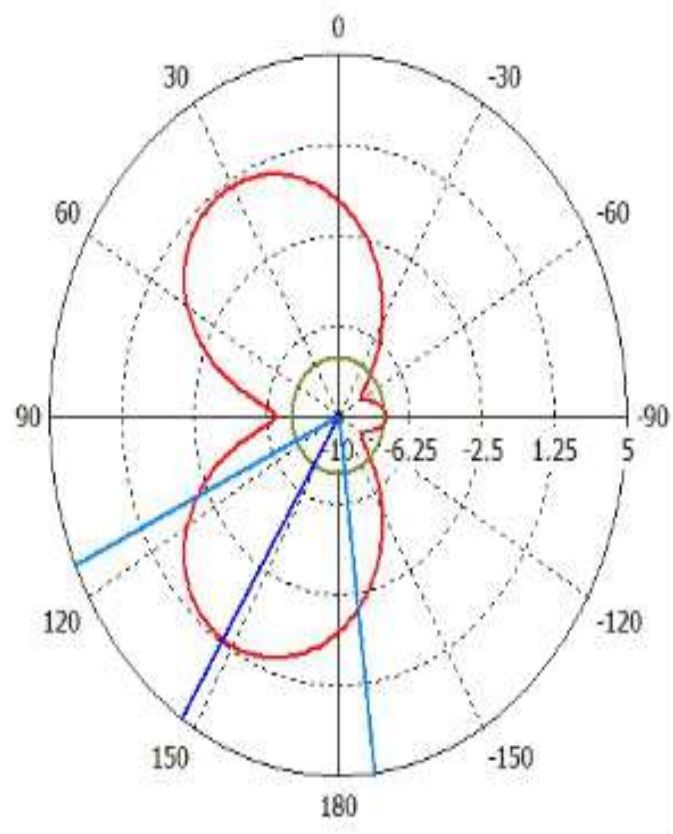

$\mathrm{H}$-Plane at $10.45 \mathrm{GHz}$

Figure 4. Radiation Patterns of the Proposed UWB Antenna at $4.99 \mathrm{GHz}, 7$ $\mathrm{GHz}, 9 \mathrm{GHz}$ and $10.45 \mathrm{GHZ}$ 


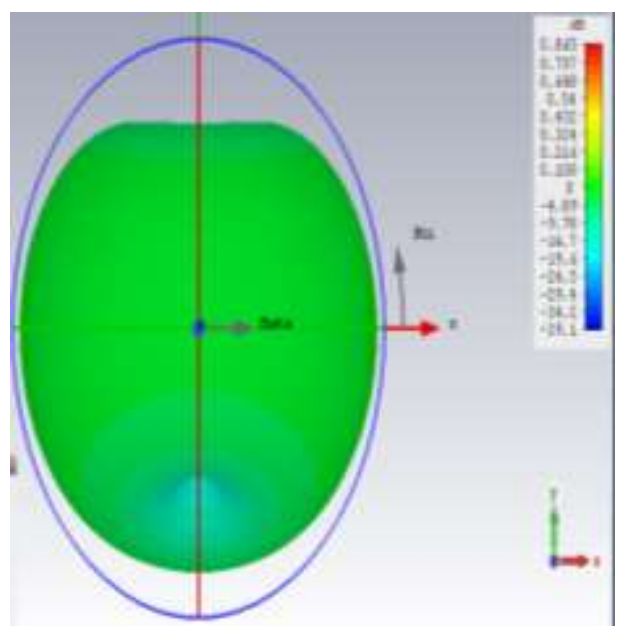

at $4.99 \mathrm{GHz}$

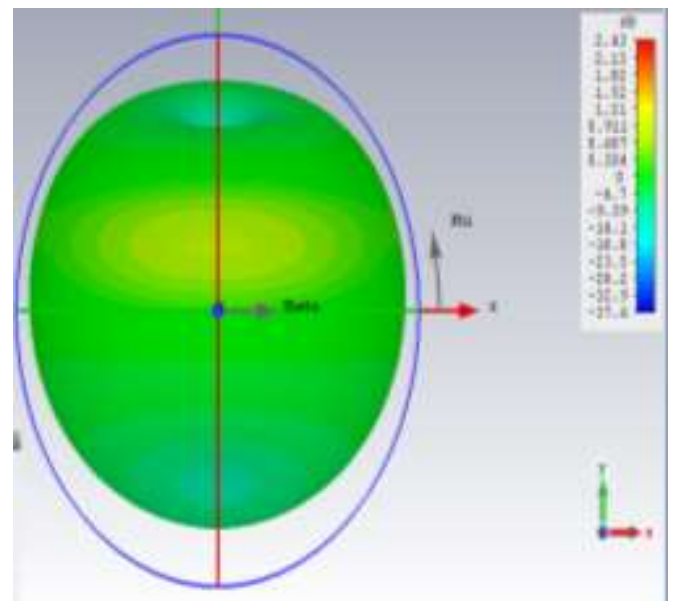

at $9 \mathrm{GHz}$

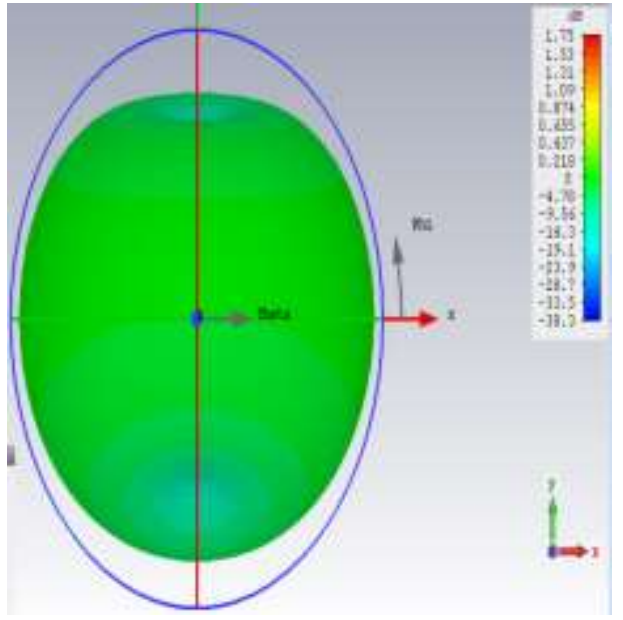

at $7 \mathrm{GHz}$

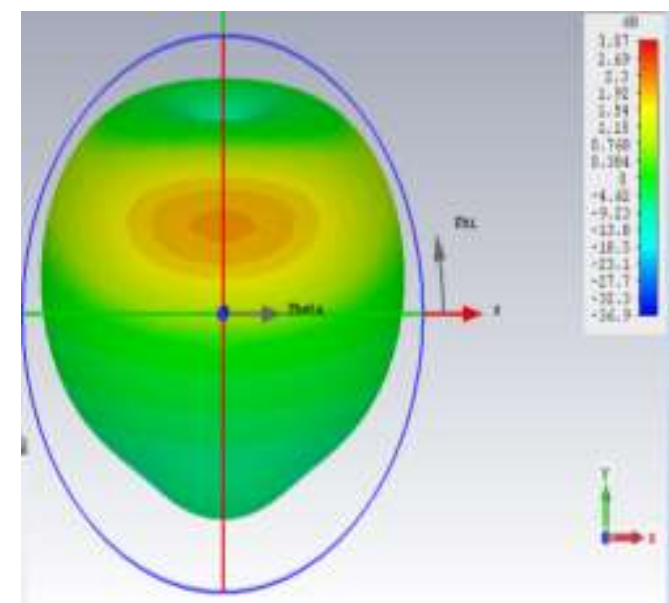

at $10.45 \mathrm{GHz}$

\section{Figure 5. 3 - Dimensional Farfield Radiation Patterns of the Proposed UWB Antenna at $4.99 \mathrm{GHz}, 7 \mathrm{GHz}, 9 \mathrm{GHz}$ and $10.45 \mathrm{GHZ}$}

\section{Conclusion and Future Scope}

In this paper, a UWB monopole antenna with Ultra Wideband characteristics is simulated and presented, by etching two L-shaped slots in the radiating patch and one square slot, two rectangular slots in the ground plane. The antenna impedance bandwidth with reflection coefficient less than $-10 \mathrm{~dB}$ is from 4.1 and $12 \mathrm{GHz}$ for VSWR $<2$ covering almost the UWB frequency band for communication systems. The antenna can be used for UWB applications since it has a bandwidth ranging from $4.1 \mathrm{GHz}$ to $12 \mathrm{GHz}$ with a stable radiation pattern. In future, this work can be extended by notching bands presented in UWB in order to reduce the interference due to existing of several narrowband wireless standards.

\section{References}

[1] FCC, Ultra-Wideband Operation FCC Report and Order, Tech. Rep.US47 CFR Part 15, (2002).

[2] Liu, W. C. and C. F. Hsu, "CPW-FED notched monopole antenna for UMTS/IMT 2000/WLAN applications", Journal Of Electromagnetic Waves And Applications, vol. 21, no. 6, (2007), pp. 841-851.

[3] L. Xie, Y. C. Jiao, Y. Q. Wei and G. Zhao, "A compact band-notched UWB antenna optimized by a novel self-adaptive differential evolution algorithm", Journal of Electromagnetic Waves and Applications, vol. 24, no. 17-18, (2010), pp. 2353-2361.

[4] A. A. L. Neyestanak, "Ultra wideband rose leaf microstrip patch antenna", Progress In Electromagnetics Research, vol. 86, (2008), pp. 155-168. 
[5] D. Ghosh, A. De, M. C. Taylor, T. K. Sarkar, M. C. Wicks and E. L. Mokole, "Transmission and Reception by Ultra-Wideband(UWB) Antennas ", IEEE Antennas and Propagation Magazine, vol. 48, no. 5, October (2006).

[6] H. Y. Xu, H. Zhang, K. Lu and X. F. Zeng, "A holly-leaf-shaped monopole antenna with low RCS for UWB application" Progress In Electromagnetics Research, vol. 1, no. 17, (2011), pp. 35-50.

[7] C. C. Lin, Y. C. Kan, L. C. Kuo and H. R. Chuang, "A planar triangular monopole antenna for UWB communication”, IEEE Microwave and Wireless Components Letters, vol. 15, no. 10, (2005), pp. 624626.

[8] M. C. Tang, T. Shi, and R. W. Ziolkowski, "Planar Ultrawideband Antennas with Improved Realized Gain Performance", IEEE Transactions on Antennas and Propagation, vol. 64, no.1, (2016) January.

[9] D. Chen and C. H. Cheng, "A Novel Compact Ultra-Wideband (UWB) Wide Slot Antenna with via Holes ”, Progress In Electromagnetics Research, PIER, vol. 94, (2009), pp. 343-349.

[10] R. Zaker, C. Ghobadi and J. Nourinia, " Novel UWB Monopole Antenna with Variable Frequency Band-Notch Function”, IEEE Antennas and Wireless Propagation Letters, vol.7, (2008).

[11] J. Jung, W. Choi and J.Choi, "A Small Wideband Microstrip-fed monopole antenna ", IEEE Microwave and Wireless Components Letters, vol. 15, (2005) October, pp.703-705.

[12] K. Chung, H. Park and J.Choi, "Wideband Microstrip-fed monopole antenna with a narrow slit ", IEEE Microwave and Optical Technology Letters, vol. 47, (2005), pp.400-402.

[13] J.N.Lee, J.H.Yoo, J.H.Kim, J.K.Park, J.S. Kim, "A Novel UWB Antenna using PI-Shaped Matching Stub for UWB Applications", IEEE International Conference on Ultra-wideband (ICUWB2008), vol. 1, (2008), pp. 109-112.

[14] Z. N. Chen, T. S. P. See and X. Qing, "Small printed Ultrawide band antenna with reduced ground plane effect", IEEE Tansactions on Antennas and Propagation, vol.53, (2007) Febuary, pp.383-388.

[15] FCC website, www.fcc.gov/pshs/techtopics/techtopics10.html.

[16] S. H. Choi and J. K. Par, "A new ultrawideband antenna for UWB applications", IEEE Microwave and Optical Technology Letters, vol. 40, (2004).

[17] B. S. Yildirim and B. A. Cetiner, "Integrated Bluetooth and UWB antenna", IEEE Antennas and Wireless Propagation Letters, vol. 8, (2009).

[18] Y. Zhang, Z. N. Chen and M.Y.W. Chia, "Effects of finite ground plane and dielectric substrate on planar dipoles for UWB applications", in proc. IEEE Int. Symp. Antennas Propagation, (2004) June, pp. 2512-2515.

[19] J. Clerk, J. Liang, C. C. Chiau, X. Chen and G. G. Parini, " Study of printed circular disc monopole antenna for UWB systems", IEEE Tansactions on Antennas and Propagation, vol. 53, (2005) November, pp. 3500-3504.

[20] K. G. Thomas, N. Lenin and R. Sivaramakrishnan, "ultrawideband planar disc monopole", IEEE Tansactions on Antennas and Propagation, vol. 54, (2006) November, pp. 1339-1341.

[21] M. J. Ammann and Z. N. Chen, "An Asymmetrical feed arrangement for Improved impedance bandwidth of planar monopole antennas", Microwave and Wireless Components Letters, vol. 40, no. 10, (2004), pp. 156-158.

[22] Z. N. Chen, M. Y. W. Chia and M. J. Ammann, "Optimization and comparision of broadband monopoles", IEE proceedings -Microwaves, Antennas and Propagation, vol. 150, (2003), pp. 429-435 .

[23] R. Chair, A. A. Kishk, K. F. Lee, C. E. Smith, and D. Kajfez, "Microstrip Line and CPW Fed Ultra Wideband Slot Antennas with U- Shaped Tuning Stub and Reflector", Progress In Electromagnetics Research, PIER, vol. 56, (2006), pp. 163-182.

[24] N. Ojaroudi, M. Ojaroudi and Y. Ebazadeh, "UWB/Omni Directional Microstrip Monopole Antenna for Microwave Imaging Applications", (2014).

[25] A. A. Eldek, "Numerical Analysis of a Small Ultra Wideband Microstrip-fed Tap Monopole Antenna", Progress In Electromagnetics Research, PIER, vol. 65, (2006).

[26] CST Microwave Studio, ver .2008, Computer Simulation Technology, Framingham, MA, (2008).

\section{Author}

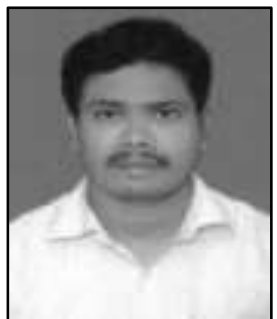

V.N. Koteswara Rao. Devana, is working as Assistant Professor in E.C.E Dept., at St. Ann's College of Engineering College \& Technology, Chirala, India. His current research interests focus on Microstrip Antennas, Broadband and UWB antenna design and analysis. He published thirteen (13) research papers in various International journals and conferences. 
International Journal of Signal Processing, Image Processing and Pattern Recognition Vol. 10, No. 1 (2017) 